faults but was nevertheless so good. It is an introduction to paediatric radiology, and is absolutely crammed with practical information and illustrations. The trouble, of course, is that radiology, like cricket or skiing, cannot be learned from a book; there is no substitute for a visit to the radiology department. Despite criticisms of the book it is very readable, any nonradiologist would find it helpful, and I would recommend it particularly to paediatricians in training.

There are three problems. Firstly, the abnormalities described are not visible in about $15 \%$ of the illustrations. The rest are good, however, and the book is almost worth having for them alone. Secondly, it is irritating to find that many captions are questions, for example. 'Multiple abnormalities detected on ultrasound. What do you see?', with the answers in an appendix. Lastly, the book lacks practical advice on when and how to use radiographs. It describes the features of epiglottitis but neglects to mention that upsetting a child with epiglottitis by sending him to the $x$ ray department may precipitate fatal respiratory obstruction. It describes the radiological features of pyloric stenosis but fails to mention how reliable or otherwise these are. It describes the radiological features of Hirschsprung's disease but does not say whether a barium enema is worth doing compared, for example, with a rectal biopsy.

T J DAVID

\section{Diagnosis and Management of Respiratory} Disorders in the Newborn. Edited by L Stern. Pp 231: \$29.95 hardback. Reading, Massachusetts, and London: AddisonWesley, 1983.

This is a strange book. About the only thing that can be said about it with certainty is that it is not a textbook on Diagnosis and Management of Respiratory Disorders in the Newborn. It consists of a series of what for a better word one might call essays, albeit well referenced essays, on certain aspects of neonatal lung disease written by a very distinguished collection of authors, all of whom concentrate on pathophysiology and diagnosis rather than treatment. Some are very good, and I would highlight the chapters by Aranda and the Montreal team on neonatal apnoea (this one actually rates five stars); by Ehrencranz and Warshaw from Yale on chronic lung disease, in particular bronchopulmonary dysplasia; and by Fanaroff and Martin from Cleveland on non-pulmonary causes of respiratory distress. Some essays wander far from the topic; that on viral pneumonia in the neonate-what a very good idea-spends a lot of time talking generally about how to diagnose virus infections and is therefore largely wasted, and that on asphyxial lung disease and meconium aspiration covers hypoxic-ischaemic encephalopathy. The shortest chapter is on respiratory distress syndrome and as such conveys little more about this major problem in neonatal care than might be gleaned from a good essay written by an MRCP candidate. There is nothing on transient tachypnoea, pulmonary haemorrhage, lung infection in ventilated babies, and perhaps most serious of all pneumothorax, interstitial emphysema, and other air leaks. Nowhere is treatment covered in anything other than the broadest general outline.

There is no point, therefore, in referring to this book for advice if you are struggling to ventilate a baby with severe respiratory distress syndrome who has developed bad interstitial emphysema. For the afficionada, however, some chapters are well worth a read.

N R C ROBERTON

Health for a change. By Sue Dowling. Pp 182: £3.95 paperback. London: Child Poverty Action Group, 1983.

This book describes a wide range of innovative schemes in preventive health care during pregnancy and early childhood. It is intended for a broad audience of planners, providers, and consumers of health services. The contents cover new initiatives from the health services, social services, education, and the voluntary sector as well as considering projects in which parents and children are active participants and are showing good examples of interdisciplinary work.

This is a very welcome publication. Many of the projects described are little known outside their own locality and there is much that others can learn from them. Many arose from impressive individual initiative and it is clear that they have had an uphill struggle for recognition and resources. Commonly, the projects have been cheap, effective, and run at field work level. Sadly too, Dr Dowling's investigation also showed that funding was often short term. ongoing support was lacking, and opportunities for evaluation were seldom available.
For those wishing to pursue further some of the 55 main projects described, the list of contacts and addresses at the end of each chapter will be most useful.

The book is extremely good value: I would certainly recommend it to child health doctors, general practitioners, and community nurses commending them to follow the initiatives reported.

L. POLNAY

Selected Writings of Sir Denis Browne. Edited by $\mathrm{H} \mathrm{H}$ Nixon, D Waterson, C A S Wink, Pp 154: $£ 10 \cdot 00$ hardback. London: Trustees of the Sir Denis Browne Memorial Fund, 1983.

Sir Denis Browne has been widely recognise as the man who established paediatric surgery in England, and in particular in London where he lived for most of his professional career. As recorded by one of his lifelong colleagues, he was adventurous, rebellious, and difficult, but with an intellectual curiosity and an intense interest in technical problems. These various aspects are portrayed in the foreword to the book. After this there is a series of carefully edited extracts from Sir Denis`s writings; with commendable brevity these illustrate his general approach. Ten pages follow on his mechanistic theory for the causation of congenital malformations and his early documentation of this is clearly presented.

The 8 papers selected for reproduction in full are on neonatal intestinal obstruction (1951), patent ductus arteriosus (1952), cleft palate and hare lip (1952), the operation for cleft palate (1932), the diagnosis of undescended testicle (1938), some congenital deformities of the rectum, anus, vagina, and urethra (1950), talipes (1950), and the pathology and classification of talipes (1959). A further selection of four of his writings completes the book. These are entitled, 'Another Place' recording the proceedings on his first visit to the House of Lords, the problem of Byron's lameness, a National Health Service, and rigid joints and rigid minds".

The book will be of interest to all paediatricians interested in the development of malformations, to all paediatric surgeons (as $D$ B are the best known initials in the specialty), and, because of his mechanistic interests, to orthopaedic surgeons, with whom his views did not always concur.

D G YOUNG 